\title{
Study on Spatial Variation of Shear Mechanical Properties of Soil-rock Mixture
}

\author{
Yanhai Wang ${ }^{1,2^{*}}$, Jianlin Li ${ }^{1,2}$, Qiao Jiang ${ }^{3}$, Yisheng Huang ${ }^{3}$, Xinzhe $\mathrm{Li}^{3}$ \\ ${ }^{1}$ Key Laboratory of Geological Hazards on Three Gorges Reservoir Area, Ministry of Education, China Three Gorges University, \\ Yichang, Hubei Province, 443002, China \\ 2 College of Civil Engineering and Architecture, China Three Gorges University, Yichang, Hubei Province, 443002, China \\ ${ }^{3}$ College of Hydraulic and Environmental Engineering, China Three Gorges University, Yichang, Hubei Province, 443002, China \\ *Corresponding author, e-mail: yanhaiwang@ctgu.edu.cn
}

Received: 02 August 2019, Accepted: 30 September 2019, Published online: 30 October 2019

\begin{abstract}
The soil-rock mixture (SRM) is a kind of special engineering geological material, which has been exposed to the field for a long time and is affected by rainwater seepage, geological force, slope sliding force and human activities, resulting in the spatial variability of its mechanical properties. Taking the SRM distributed on a slope of the Three Gorges Reservoir area as the research object, four test locations were selected along and transverse the slope. First, in-situ large-scale direct shear test was carried out, and then the laboratory large-scale direct shear test, particle sieving test, and water content test were carried out in the undisturbed sample to study the variation of shear mechanical properties of SRM distributed in different spatial locations. The results show that: (1) Under the same normal stress, the peak strength of the SRM decreases at a similar rate along the slope direction and the transverse slope direction. (2) The cohesion of the SRM is continuously strengthened, and the friction angle is continuously deteriorated along the slope from high to low, the cohesion and friction angle are almost no variability along the transverse slope. (3) The mechanism of the abovementioned variation in the shear mechanics parameters of SRM is that the lower the elevation along the slope, the more fragmented the rock, the lower the rock content. (4) Spatial variability models of cohesion and friction angle of SRM were established, which can provide references for related engineering applications.
\end{abstract}

\section{Keywords}

soil-rock mixture, large-scale direct shear test, shear mechanical parameters, spatial variation, rock content

\section{Introduction}

The SRM consists of low-strength soils, high-strength rock blocks, and pores. It is a special engineering geological material widely distributed in slope engineering to form an SRM slope [1-3]. The SRM slope is exposed to the field and has long been affected by rainwater seepage, geological force, slope sliding force and human activities, resulting in differences in mechanical properties of SRM distributed in different spatial locations [4-5].

Many scholars believe that the mechanical properties of geological materials are one of the key data for evaluating the stability of slopes. Considering the spatial variability of the mechanical properties of geological materials, it is helpful to improve the reliability of slope stability calculation results [6-9].

In recent years, scholars have used probability theory and statistical analysis methods to study the spatial distribution and variability of mechanics parameters of soil and rock mass. Lumb [10] through the statistical analysis of the cohesion and friction angle of soils with different depths, believed that the shear strength parameters obey the Beta distribution. Tang et al. [11] carried out statistical analysis of in-situ direct shear test of 1139 groups rock mass and determined that the best probability distribution model of shear strength parameters is log-normal distribution, indicating that the shear strength parameters had great variability under the influence of rock mass quality. Rahardjo et al. [12], Uzielli et al. [13], studied the variability of soil mechanical properties along the direction of burial depth based on in-situ and laboratory tests. Brejda et al. [14] proposed that in the regional context, the soil properties do not conform to the normal distribution, but to the log-normal distribution. Wang et al. [15] made statistical analysis on the normal stress and shear stress in the 
direct shear test of the same type of rock mass, established a two-dimensional normal distribution model of normal stress and shear stress. Cheng et al. [16] studied the uncertainty and variability of mechanical parameters of jointed rock mass based on mechanics test and in-situ survey data. Samui et al. [17] used the adaptive neuro-fuzzy inference system and multivariate adaptive regression splines to establish a spatial variability prediction model for the rock in the Bangalore region along the depth direction. These studies show that the mechanical properties of geomaterials have spatially variability that cannot be ignored.

In the study of the mechanical properties of SRM, the effects of rock content, water content, shear rate, and rock block size on the shear mechanical parameters of SRM was mainly studied. Zhao et al. [18], Yan et al. [19], Vallejo et al. [20] respectively studied the law of influence of rock content on shear strength, cohesion and friction angle of SRM by using discrete element simulation analysis and laboratory direct shear test. Wei et al. [21], Xu et al. [22] used in-situ and laboratory large-scale direct shear tests to study the macroscopic mechanical properties and microstructure characteristics of SRM with different water content and different shear rates. Zhang et al. [23] through triaxial tests on SRM containing oversize rock blocks, revealing that the breakage and interlocking of oversize rock blocks are two important factors controlling the mechanical properties of SRM. The above research objects were mainly laboratory disturbance or undisturbed SRM samples at a certain position, and almost no consideration is given to the variability of the mechanical properties of the SRM distributed at different locations in space.

In this paper, the SRM distributed at different locations on the slope were taken as the research object. Large-scale direct shear tests were carried out on site, and large-scale direct shear tests, water content tests, particle grading tests and natural density tests were carried out in laboratory on the undisturbed SRM samples. Experiments were carried out to study the evolution law of shear mechanical properties of SRM along and transverse the slope. Finally, the spatial evolution models of cohesive and friction angle of SRM were given.

\section{Experiment Scheme}

Due to the simple structure and convenient operation of direct shear test equipment, it is widely used to test the shear strength parameter of geomaterials [24]. The main test methods used in this paper are large-scale direct shear test on site and in the laboratory.

\subsection{In-situ large-scale direct shear test scheme}

\subsubsection{In-situ test equipment system}

In-situ direct shear test was carried out on the SRM using a self-made large-scale direct shear test equipment system, which consists of vertical and horizontal reaction frame, vertical and horizontal loading jacks, shear boxes, dial indicators, and sliding tracks, as shown in Fig. 1. The shape of the shear boxes is square, the length and width are $500 \mathrm{~mm}$, and the upper and lower shear boxes heights are each $200 \mathrm{~mm}$.

\subsubsection{In-situ test locations selection}

Four locations were selected to carry out in-situ large-scale direct shear tests. The test locations are numbered YWZJ1, YWZJ2, YWZJ3, and YWZJ4, and the corresponding elevation are $170.7 \mathrm{~m}, 176.7 \mathrm{~m}, 186.4 \mathrm{~m}$, and $189.7 \mathrm{~m}$, as shown in Fig. 2. The three test locations of YWZJ4, YWZJ2, and YWZJ1 are distributed along the slope from high to low, YWZJ4 and YWZJ3 are distributed along the transverse slope. On the third day after the completion of the tests, the YWZJ1 was submerged by the Yangtze River.

\subsubsection{In-situ sample preparation}

According to the size of the shear boxes, the samples were prepared at the selected locations, 3 samples were prepared at each test location, a total of 12 samples were made, as shown in Fig. 3.

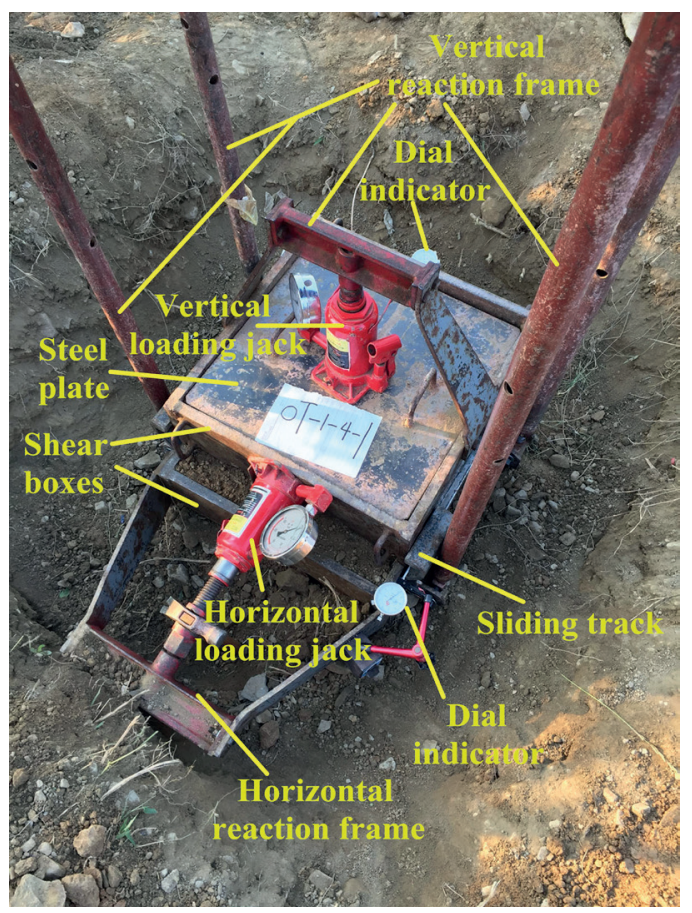

Fig. 1 In-situ large-scale direct shear test equipment system 

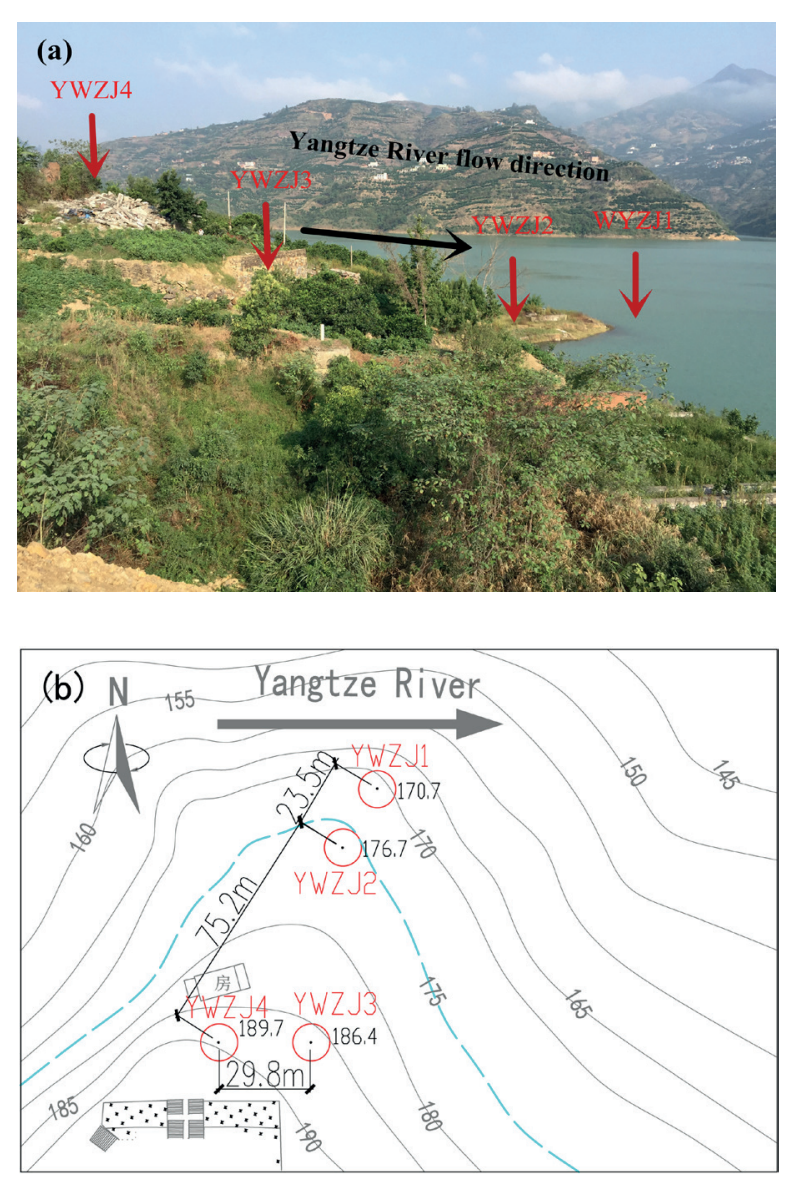

Fig. 2 Location distribution of in-situ direct shear test.

(a) Photo of the scene, (b) Plan
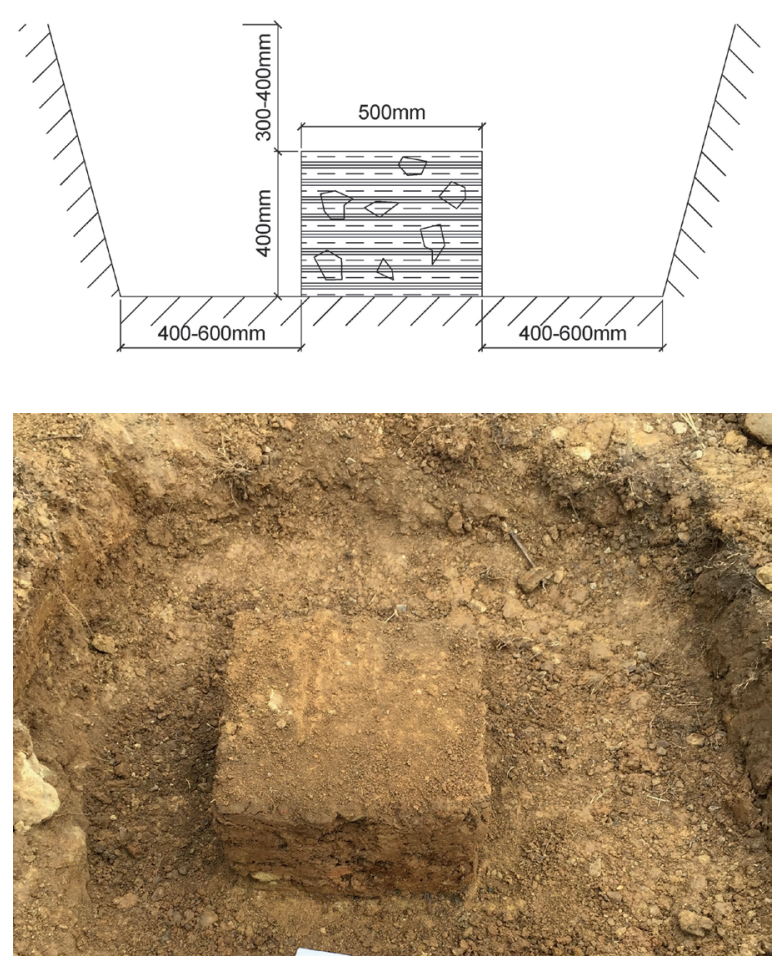

Fig. 3 Preparation of in-situ direct shear samples

\subsection{Laboratory large-scale direct shear test scheme 2.2.1 Laboratory test equipment system}

The laboratory direct shear tests were carried out on the SRM by using a large-scale direct shear equipment controlled by a microcomputer. The equipment is mainly composed of a hydraulic loading system, data measurement and acquisition system, reaction frame, shear boxes, etc., as shown in Fig. 4. The inner diameter of the shear boxes is $250 \mathrm{~mm}$ and the height is $200 \mathrm{~mm}$. Rollers are arranged at the bottom of the lower shear box. The upper shear box is fixed, and the lower shear box is moved during the shear process.

\subsubsection{Laboratory samples preparation}

In order to improve the reliability of the laboratory test data, 4 undisturbed samples were taken at each in-situ test location, a total of 16 samples for laboratory direct shear test. The diameter of the SRM samples is $240 \mathrm{~mm}$ and the height is $200 \mathrm{~mm}$. In order to ensure the integrity of the samples, a PVC pipe with an inner diameter of $240 \mathrm{~mm}$ and a height of $200 \mathrm{~mm}$ is placed outside each sample, and a pre-cut shear channel with a width of $40 \mathrm{~mm}$ was cut in the middle of the PVC pipe. Three vertical supports were arranged at equal intervals within the width of the pre-cut shear channel, as shown in Fig. 5.

\section{Results analysis of the tests}

3.1 Results analysis of in-situ large-scale direct shear tests The three samples at the same test location were subjected to the normal stress of $50.86 \mathrm{kPa}, 76.30 \mathrm{kPa}$, and $101.73 \mathrm{kPa}$. The shearing direction was performed along the slope. The shearing was completed when the shear displacement reached $15 \%$ of the sample width.

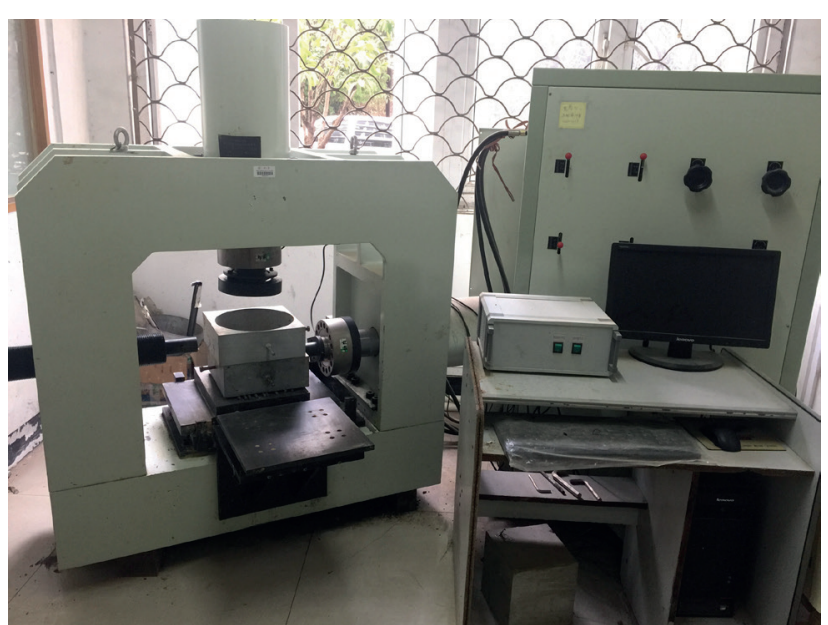

Fig. 4 Microcomputer controlled large-scale direct shear equipment 

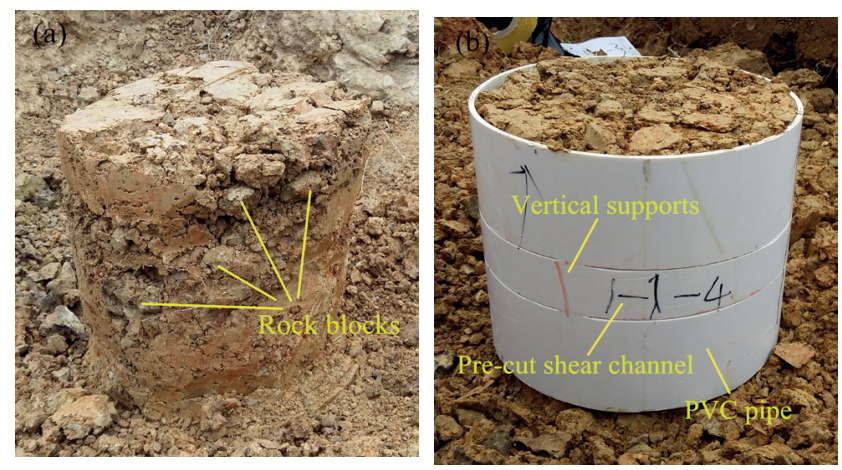

Fig. 5 Undisturbed SRM sample (a) SRM sample before inserting PVC pipe; (b) SRM sample after inserting the PVC pipe

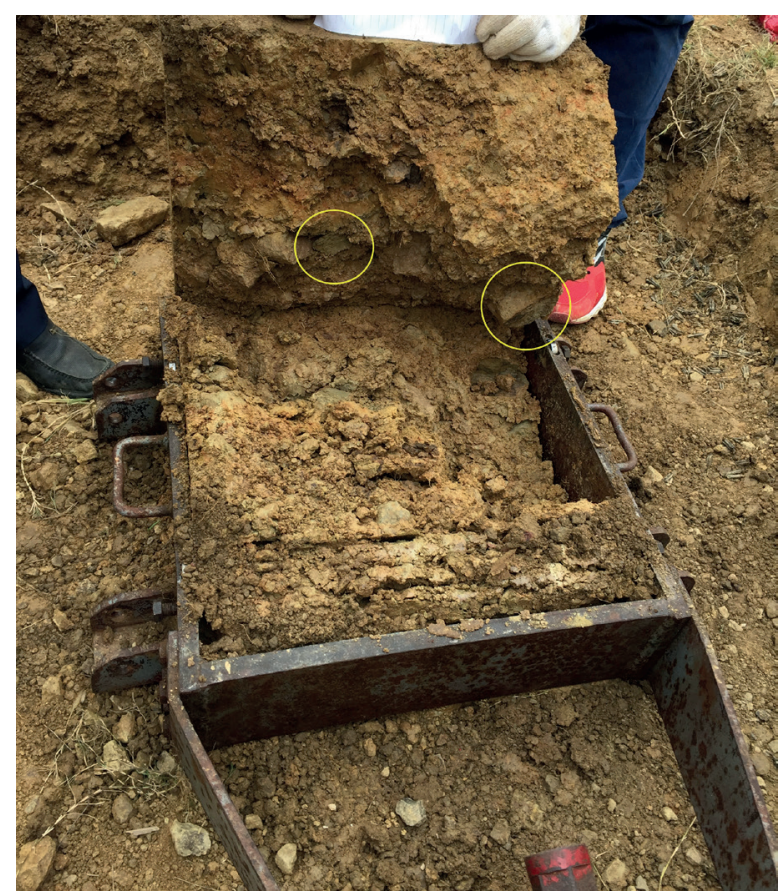

Fig. 6 Typical shear surface in the in-situ test

The typical shear failure surface of the SRM is shown in Fig. 6. The shear surface has obvious undulations, and some of the rock blocks have been completely cut off.

The shear stress-shear displacement curve under the same normal stress at different test locations are shown in Fig. 7.

As can be seen from Fig. 7, the peak strength of different test locations satisfies a certain law under the same normal stress. In order to show this law more intuitively, the curves of peak strength with four test locations under three normal stress conditions are drawn, as shown in Fig. 8. It can be seen from Fig. 8 that under different normal stresses, the peak strength increases with the increase of normal stress, and the 4 test locations have the same pattern. Under the same normal stress, along the slope,
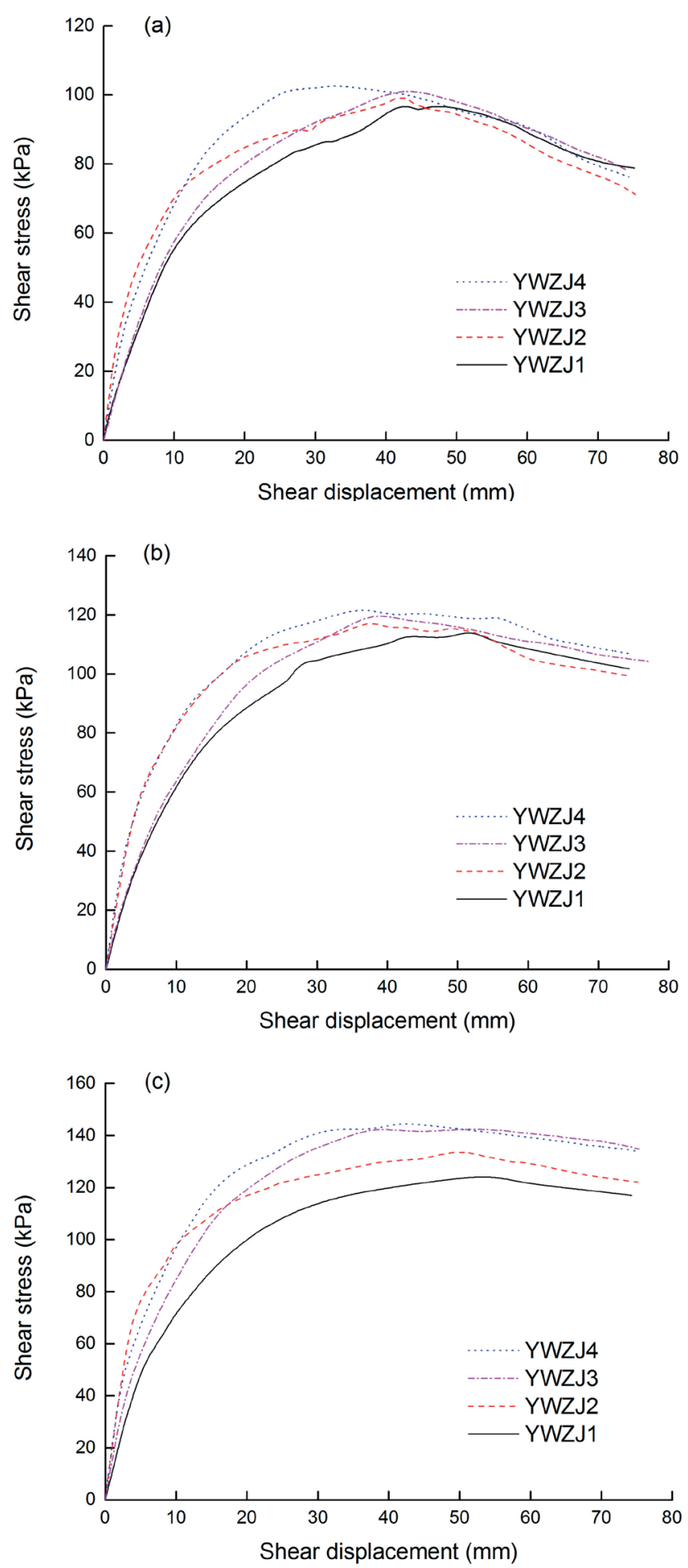

Fig. 7 Shear stress-shear displacement curve of the in-situ large-scale direct shear test. (a) $50.86 \mathrm{kPa}$, (b) $76.30 \mathrm{kPa}$, (c) $101.73 \mathrm{kPa}$

the peak strength decreases gradually from YWZJ4 to YWZJ2, YWZJ2 to YWZJ1, and the decreasing rate from YWZJ4 to YWZJ2 is less than the decreasing rate from YWZJ2 to YWZJ1. Under the same normal stress, along the transverse slope, the peak strength decreases gradually from YWZJ4 to YWZJ3. 


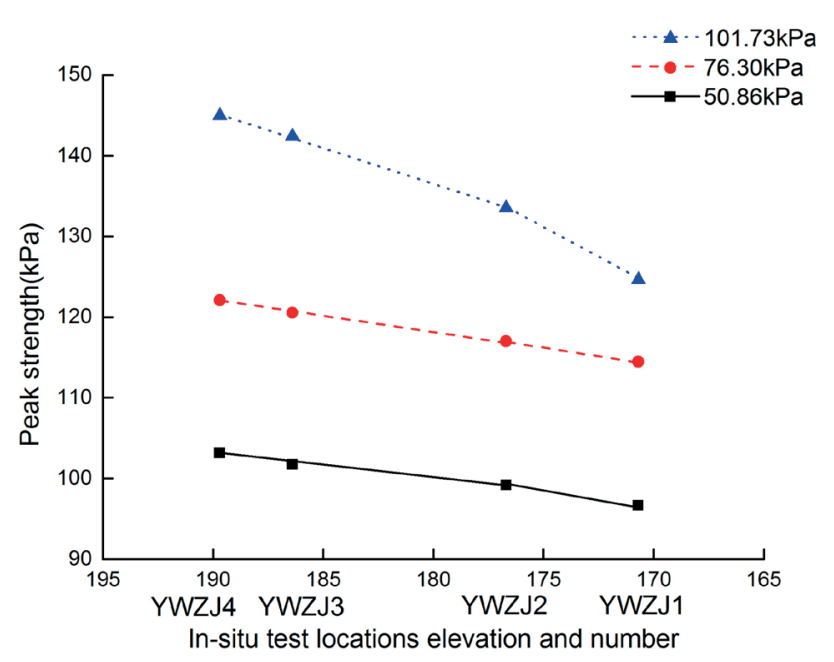

Fig. 8 Peak strength change curves at four in-situ test locations

Based on the in-situ large-scale direct shear test results and the Mohr Coulomb criterion, the cohesion and friction angle of the four test locations were obtained, as shown in Tables 1-2.

In order to analyze the variation law of the cohesion and friction angle of the SRM in the slope, the degree of deterioration is used to indicate the degree of decrease of shear strength parameters, and the degree of strengthening is used to indicate the degree of increase of the shear strength parameters. As in the Eqs. (1)-(4).

$$
\begin{aligned}
& L_{i}=\frac{l_{z}-l_{i}}{H_{z}-H_{i}}, \quad i=n, \ldots, 2,1 \\
& \Delta L_{i}=\frac{l_{i+1}-l_{i}}{H_{i+1}-H_{i}}, \quad i=n, \ldots, 2,1 \\
& Q_{i}=\frac{q_{i}-q_{z}}{H_{z}-H_{i}}, \quad i=n, \ldots, 2,1 \\
& \Delta Q_{i}=\frac{q_{i}-q_{i+1}}{H_{i+1}-H_{i}}, \quad i=n, \ldots, 2,1
\end{aligned}
$$

Where $L_{i}$ is the total deterioration degree of the parameters, $\Delta L_{i}$ is the stage deterioration degree of the parameters, $l_{z}$ is the shear strength parameters obtained at the reference test location, $l_{i}$ and $l_{i+1}$ are the shear strength parameters obtained at other test locations, $i$ is test location number, $H_{z}$ is elevation of reference test location, $H_{i}$ and $H_{i+1}$ are elevation of other test locations, $Q_{i}$ is the total strengthening degree of the parameters, $\Delta Q_{i}$ is the stage strengthening degree of the parameters, $q_{z}$ is the shear strength parameters obtained at the reference test location, $q_{i}$ and $q_{i+1}$ are the shear strength parameters obtained at other test locations.

Taking the shear strength parameters of the highest test point YWZJ4 as the reference test location, calculate the total strengthening degree and stage strengthening degree of cohesion, total deterioration degree and stage deterioration degree of friction angle, along slope direction YWZJ4 $(i=3)$, YWZJ2 $(i=2)$, YWZJ1 $(i=1)$, and transverse slope direction YWZJ4 $(i=2)$, YWZJ3 $(i=1)$. The results are summarized in Table 1, Table 2 and Fig. 9. Since there are only two test locations in the transverse slope direction, the total strengthening degree, the total deterioration degree,

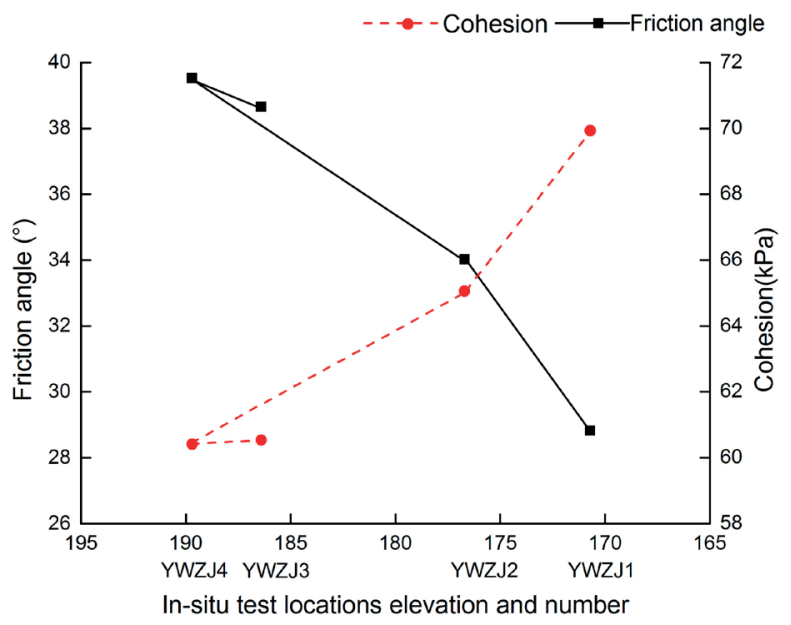

Fig. 9 The evolution law of cohesion and friction angle in the in-situ direct shear tests

\begin{tabular}{|c|c|c|c|c|c|}
\hline Test location number & Elevation of test location (m) & $c(\mathrm{kPa})$ & Total strengthening degree $(\mathrm{kPa} / \mathrm{m})$ & $\varphi\left({ }^{\circ}\right)$ & Total deterioration degree $(\% / \mathrm{m})$ \\
\hline YWZJ4 & 189.7 & 60.41 & - & 39.52 & - \\
\hline YWZJ3 & 186.4 & 60.54 & 0.04 & 38.65 & 0.26 \\
\hline
\end{tabular}

Table 1 Cohesion and friction angle of the in-situ test along slope

\begin{tabular}{lcccccc}
\hline $\begin{array}{l}\text { Test location } \\
\text { number }\end{array}$ & $\begin{array}{c}\text { Elevation of test } \\
\text { location }(\mathrm{m})\end{array}$ & $c(\mathrm{kPa})$ & $\begin{array}{c}\text { Total strengthening } \\
\text { degree }(\mathrm{kPa} / \mathrm{m})\end{array}$ & $\begin{array}{c}\text { Stage strengthening } \\
\text { degree }(\mathrm{kPa} / \mathrm{m})\end{array}$ & $\begin{array}{c}\varphi\left({ }^{\circ}\right) \\
\text { Total deterioration } \\
\text { degree }(\% / \mathrm{m})\end{array}$ & $\begin{array}{c}\text { Stage deterioration } \\
\text { degree }(\% / \mathrm{m})\end{array}$ \\
\hline YWZJ4 & 189.7 & 60.41 & - & 0.36 & 39.52 & - \\
YWZJ2 & 176.7 & 65.06 & 0.36 & 0.81 & 28.02 & 0.42 \\
YWZJ1 & 170.7 & 69.93 & 0.50 & 0.42 & 0.56 \\
\hline
\end{tabular}

Table 2 Cohesion and friction angle of the in-situ test along the transverse slope 
the stage strengthening degree, and the stage deterioration degree value are the same, so only the total strengthening degree and the total deterioration degree are listed in Table 2.

As can be seen from Tables 1-2 and Fig. 9 that the evolution law of the shear strength parameters of the SRM along the slope to the test locations YWZJ4, YWZJ2, YWZJ1 is that the cohesion increases from $60.41 \mathrm{kPa}$ to $69.93 \mathrm{kPa}$, showing a trend of continuous strengthening; the friction angle decreased from $39.52^{\circ}$ to $28.81^{\circ}$, showing a trend of continuous deterioration. The evolution law of the shear strength parameters of SRM along the transverse slope to the test locations YWZJ4, YWZJ3 is that the cohesion increases from $60.41 \mathrm{kPa}$ to $60.54 \mathrm{kPa}$, which is a certain strengthening but not obvious; the friction angle is reduced from $39.52^{\circ}$ to $38.65^{\circ}$, the deterioration trend is more obvious than the strengthening tendency of cohesion. In general, the variability of the shear strength parameters of the SRM along the slope direction is greater than that of the transverse slope direction.

In order to further study the influence of spatial location on the shear strength parameters of SRM, large-scale direct shear test, particle sieving test, density test and water content test were carried out on undisturbed samples in the laboratory.

\subsection{Analysis of laboratory test results}

\subsubsection{Analysis of laboratory large-scale direct shear test results}

Before carrying out the direct shear test, it was necessary to remove the shear channel on the PVC pipe outside the undisturbed SRM sample to avoid the influence of the PVC pipe on the shear surface. Three vertical supports were reserved to prevent misalignment of PVC pipe during normal force application. One transverse joint was cut on each of the three vertical supports to reduce the influence of the vertical supports on shear strength, as shown in Fig. 10.

The treated undisturbed SRM sample was placed in a shear box according to the indicated direction, and normal stresses of $100 \mathrm{kPa}, 200 \mathrm{kPa}, 300 \mathrm{kPa}$, and $400 \mathrm{kPa}$ were applied to each of the four samples at each test location. When the shear displacement reached $15 \%$ of the sample diameter, the shear was completed.

The undisturbed samples of the SRM were numbered SNZJ1, SNZJ2, SNZJ3, and SNZJ4, and the corresponding test locations elevation were 170.7, 176.7, 186.4, and 189.7, respectively. The shear stress and displacement curves of the same normal stress corresponding to different test locations are shown in Fig. 11.

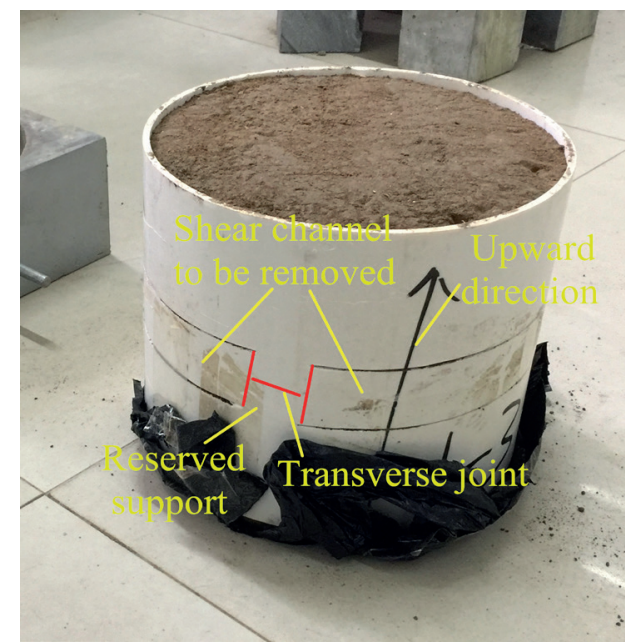

Fig. 10 Schematic diagram of undisturbed sample treatment

It can be seen from Fig. 11 that under the same normal stress, the variation law of the peak strength at different test locations is consistent with the in-situ direct shear test. In order to show this variation law more intuitively, the curve of peak strength changing with four test locations under three normal stress conditions is drawn, as shown in Fig. 12. It can be seen from Fig. 12 that under different normal stresses, the peak strength increases with the increase of normal stress, the change laws of the four test locations are consistent. Under the same normal stress, along the slope direction, the peak strength gradually decreases from SNZJ4 to SNZJ2, and fromSNZJ2 to SNZJ1. The decreasing rate from SNZJ4 to SNZJ2 is less than the decreasing rate from SNZJ2 to SNZJ1. Under the same normal stress, along the transverse slope, the peak strength gradually decreases from SNZJ4 to SNZJ3, and the decreasing rate is basically consistent with that of SNZJ4 to SNZJ2.

The method of processing in-situ direct shear test results was used to process the results of laboratory direct shear test, the total strengthening degree and stage strengthening degree of cohesion, total deterioration degree and stage deterioration degree of friction angle were calculated respectively. The results are summarized in Table 3, Table 4 and Fig. 13.

It can be seen from Table 3-4 and Fig. 13 that the shear strength parameters of the SRM increase along the slope to the test locations SNZJ4, SNZJ2 and SNZJ1. The cohesion increases from $54.67 \mathrm{kPa}$ to $66.25 \mathrm{kPa}$, which is continuously strengthened trend; the internal friction angle decreased from $34.27^{\circ}$ to $27.02^{\circ}$, showing a trend of continuous deterioration. The evolution law of shear strength parameters of SRM along the transverse slope to the test locations SNZJ4 and SNZJ3 is that the cohesion increases 

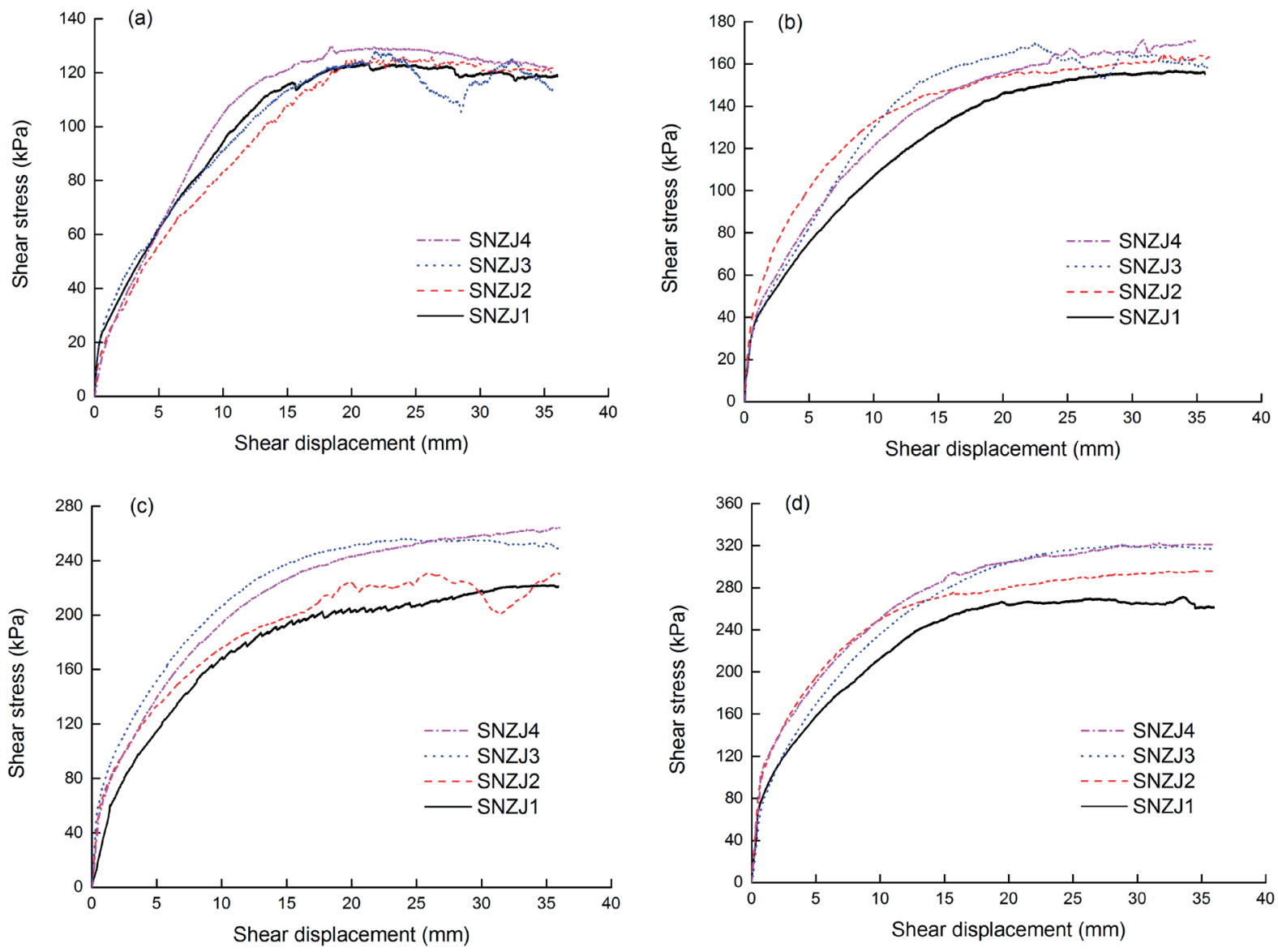

Fig. 11 Shear stress-shear displacement curve of the laboratory large-scale direct shear test. (a) $100 \mathrm{kPa}$, (b) $200 \mathrm{kPa}$, (c) $300 \mathrm{kPa}$, (d) $400 \mathrm{kPa}$

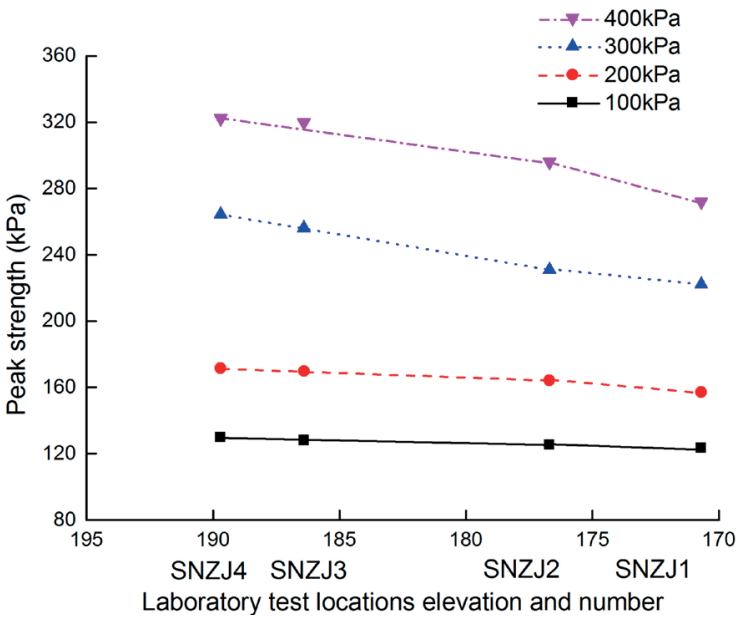

Fig. 12 Peak strength change curve of laboratory test

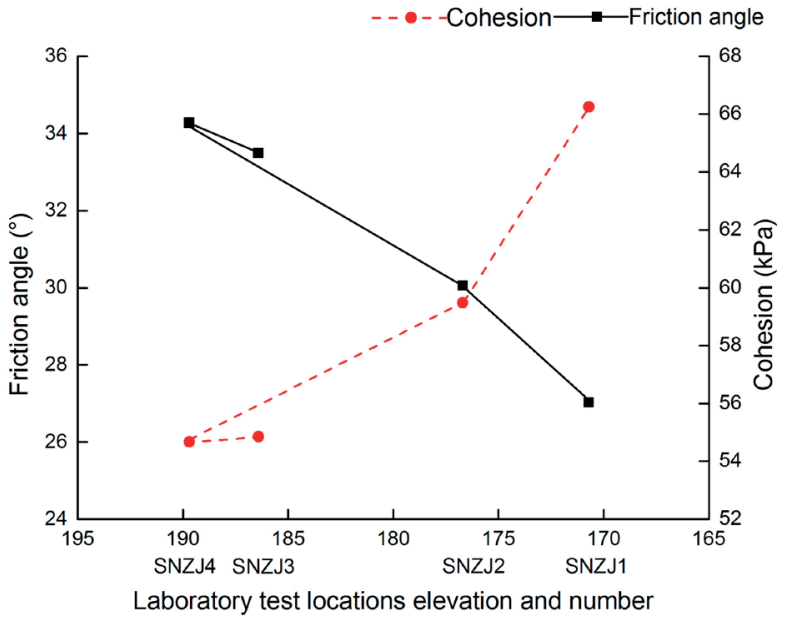

Fig. 13 The law of cohesion and friction angle evolution laboratory direct shear tests

Table 3 Cohesion and friction angle of laboratory test along slope

\begin{tabular}{lcccccc}
\hline $\begin{array}{l}\text { Test location } \\
\text { number }\end{array}$ & $\begin{array}{c}\text { Elevation of test } \\
\text { location }(\mathrm{m})\end{array}$ & $c(\mathrm{kPa})$ & $\begin{array}{c}\text { Total strengthening } \\
\text { degree }(\mathrm{kPa} / \mathrm{m})\end{array}$ & $\begin{array}{c}\text { Stage strengthening } \\
\text { degree }(\mathrm{kPa} / \mathrm{m})\end{array}$ & $\begin{array}{c}\varphi\left({ }^{\circ}\right) \\
\text { Total deterioration } \\
\text { degree }(\% / \mathrm{m})\end{array}$ & $\begin{array}{c}\text { Stage deterioration } \\
\text { degree }(\% / \mathrm{m})\end{array}$ \\
\hline SNZJ4 & 189.7 & 54.67 & - & - & 34.27 & - \\
SNZJ2 & 176.7 & 59.48 & 0.37 & 0.37 & 30.05 & 0.32 \\
SNZJ1 & 170.7 & 66.25 & 0.61 & 1.13 & 27.02 & 0.38 \\
\hline
\end{tabular}


Table 4 Cohesion and friction angle of laboratory test along the transverse slope

\begin{tabular}{|c|c|c|c|c|c|}
\hline Test location number & Elevation of test location (m) & $\mathrm{c}(\mathrm{kPa})$ & Total strengthening degree $(\mathrm{kPa} / \mathrm{m})$ & $\varphi\left(^{\circ}\right)$ & Total deterioration degree $(\% / \mathrm{m})$ \\
\hline SNZJ4 & 189.7 & 54.67 & - & 34.27 & - \\
\hline SNZJ3 & 186.4 & 54.85 & 0.05 & 33.48 & 0.24 \\
\hline
\end{tabular}

from $54.67 \mathrm{kPa}$ to $54.85 \mathrm{kPa}$, which is a certain strengthening but not obvious; the internal friction angle is reduced from $34.27^{\circ}$ to $33.48^{\circ}$, the deterioration trend is more obvious than the strengthening tendency of cohesion. In general, the variability of the shear strength parameters of the SRM along the slope direction is greater than that of the transverse slope direction.

\subsubsection{Evolution mechanism analysis}

The factors affecting the shear strength parameters of the SRM include rock block properties, shear rate, water content, compactness, and rock content. Because the test locations are selected in the same geological layer on the same slope, the soil in the SRM sample is clay, the rock blocks are all sandstone and siltstone with the same properties. Therefore, the influence of the properties of soil and rock blocks on the shear strength parameters of the sample was not considered. The shear rate was controlled at $1 \mathrm{~mm} / \mathrm{min}$ in both the in-situ and laboratory large-scale direct shear tests. The shear rate was the same, and the influence of the shear rate on the shear strength parameters of the SRM was also not considered. In this paper, the evolution mechanism of the shear strength parameters of the SRM in different spatial locations was studied by testing the water content, compactness, and rock content of the samples.

The water content, natural density and particle sieving test of the samples at four test locations SNZJ4, SNZJ3, SNZJ2, and SNZJ1 were sequentially numbered. The water content test was numbered SNWC4, SNWC3, SNWC2, SNWC1, and the natural density test was numbered SNDS4, SNDS3, SNDS2, SNDS1, particle sieving test was numbered SNRC4, SNRC3, SNRC2, SNRC1. The water content and natural density of the undisturbed SRM samples were measured, as shown in Tables 5-6.

Table 5 Water content of undisturbed SRM

\begin{tabular}{lcccc}
\hline Number & SNWC4 & SNWC3 & SNWC2 & SNWC1 \\
\hline Water content (\%) & 15.39 & 15.15 & 15.67 & 16.61 \\
Standard deviation & \multicolumn{4}{c}{0.554} \\
\hline
\end{tabular}

Table 6 Natural density of undisturbed SRM

\begin{tabular}{lcccc}
\hline Number & SNDS4 & SNDS3 & SNDS2 & SNDS1 \\
\hline Natural density $\left(\mathrm{g} \cdot \mathrm{cm}^{-3}\right)$ & 1.905 & 1.896 & 1.921 & 1.940 \\
Standard deviation & \multicolumn{4}{c}{0.017} \\
\hline
\end{tabular}

As can be seen from Table 5, the water contents of the SRM at the four test locations are between $15.15 \%$ and $16.61 \%$. The water content of SRM at the SNZJ1 test location is the highest, while the water content of the SRM at the other three test locations is close. The main reason is that the SNZJ1 test location is closest to the Yangtze River. The standard deviation of the water content of the SRM at the four test locations is 0.554 , indicating that the water content deviation was not large. It can be seen from Table 6 that the natural density of the SRM at the four test locations are between $1.940 \mathrm{~g} \cdot \mathrm{cm}^{-3}$ and $1.896 \mathrm{~g} \cdot \mathrm{cm}^{-3}$, and the standard deviation is 0.017 , indicating that the natural density deviation is small. Based on the above analysis, the water content and natural density of the SRM samples at the four test locations have little difference, which is not the fundamental cause for the evolutionary law of the shear strength parameters.

In order to avoid the impact on the original rock content of SRM caused by the broken rock blocks in the process of direct shear test, the SRM beyond $200 \mathrm{~mm}$ from the shear surface was taken as the test object for particle sieving test. The grading curves of undisturbed SRM at four test locations are shown in Fig. 14, and the calculated unevenness coefficient and curvature coefficient are shown in Table 7.

According to the scholars put forward the classification standard of soil and rock blocks which is related to the characteristic size of SRM engineering $[25,26]$. In this paper, a cylindrical shear box with a diameter of $250 \mathrm{~mm}$ and a height of $100 \mathrm{~mm}$ was selected for the direct shear test of SRM. Therefore, the threshold value $d_{\mathrm{thr}}=5 \mathrm{~mm}$ for the boundary between soil and rock blocks, and the maximum particle size of rock blocks should not exceed $75 \mathrm{~mm}$. See Table 8 for the rock content of each original sample. The rock contents of the undisturbed SRM at different test locations are different, among which the rock contents of SNRC4, SNRC2 and SNRC1 differ greatly, while the rock contents of SNRC4 and SNRC3 are almost equal. This may be because the lower the elevation along

Table 7 Unevenness coefficient and curvature coefficient of undisturbed SRM samples

\begin{tabular}{lcccc}
\hline Number & SNRC4 & SNRC3 & SNRC2 & SNRC1 \\
\hline Curvature coefficient $\left(\mathrm{C}_{\mathrm{c}}\right)$ & 0.87 & 0.67 & 0.93 & 0.33 \\
Unevenness coefficient $\left(\mathrm{C}_{\mathrm{u}}\right)$ & 27.42 & 48.57 & 26.77 & 24.97 \\
\hline
\end{tabular}




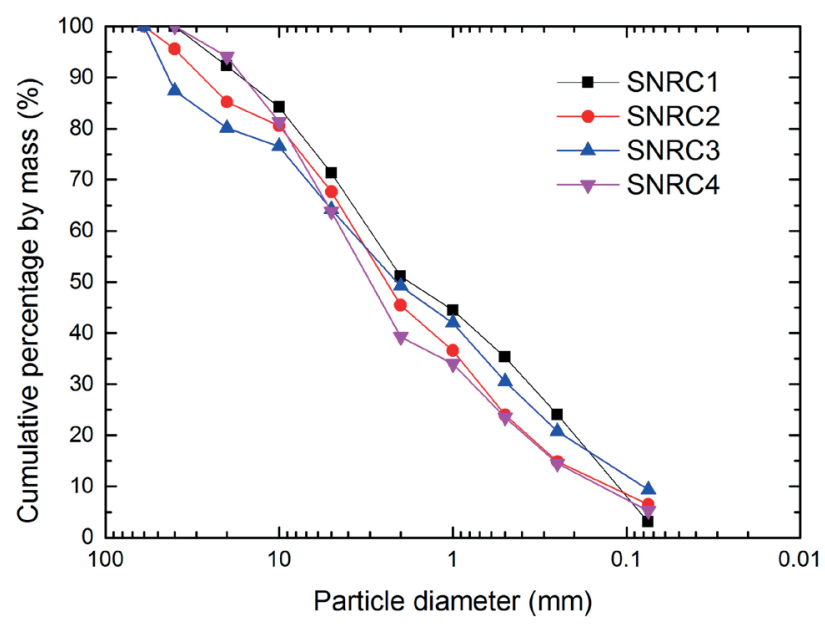

Fig. 14 Grading curves of undisturbed SRM samples

Table 8 Rock content of undisturbed SRM samples

\begin{tabular}{lcccc}
\hline Number & SNRC4 & SNRC3 & SNRC2 & SNRC1 \\
\hline Rock content (\%) & 36.20 & 35.80 & 32.30 & 28.70 \\
\hline
\end{tabular}

the slope, the greater the thrust, and the rock blocks in the SRM are more broken and the particle size is smaller, so the rock content is lower. In addition, the seepage and drag action of rainwater in the slope, which brings fine particles in the SRM from high to low, which is also the reason for the decrease of the rock content of SRM along the slope.

Many scholars have studied the effect of rock on the shear mechanical properties of the SRM. The results show that when the rock content is less than $40 \%$, the cohesive increases with the decrease of the rock content, and the friction angle decreases with the decrease of rock content $[18,27]$. The experimental results in this paper are consistent with the existing research results, as shown in Fig. 15.

\section{Evolution law of shear strength parameters}

According to the analysis of the cohesive and friction angle of the SRM at the four test locations measured by the in-situ test and the laboratory test, the cohesive and friction angle of the three test locations along the slope change greatly and cannot be ignored. However, the cohesion and friction angle of the two test locations along the transverse slope hardly changed, which can be ignored.

If the cohesive and friction angle of SRM change continuously along the slope direction, the evolution models of cohesion and friction angle with elevation can be established according to the test results. The test results are shown in Table 9.

Since the in-situ test results are larger than the laboratory test results, it is necessary to establish the evolution models of cohesion and friction angle with elevation respectively.
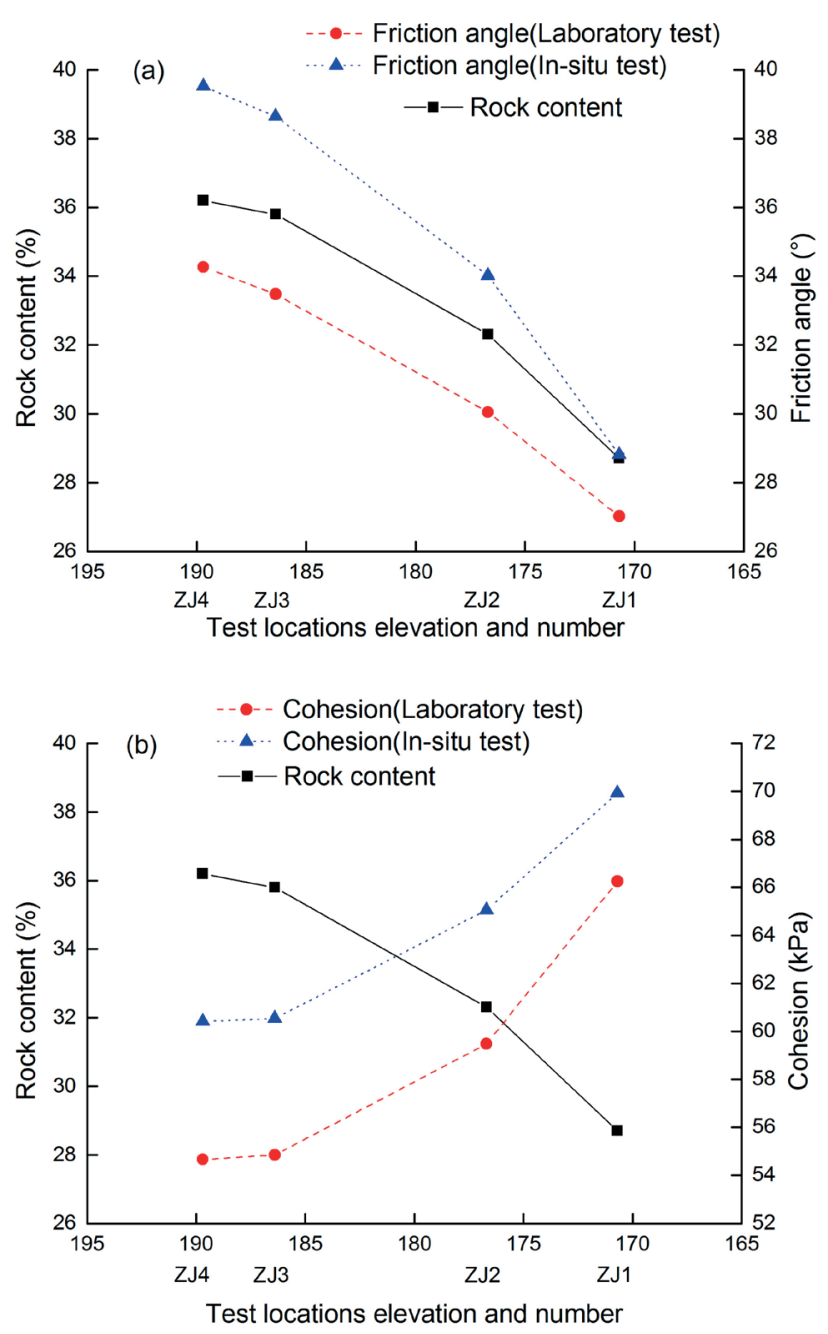

Fig. 15 Variation of shear strength parameters with rock content. (a) Variation of friction Angle with rock content, (b) Variation of cohesion with rock conten

Table 9 In-situ and laboratory test results

\begin{tabular}{lccccc}
\hline Number & $\begin{array}{c}\text { Elevation of test } \\
\text { location }(\mathrm{H} / \mathrm{m})\end{array}$ & \multicolumn{2}{c}{$\begin{array}{c}\text { In-situ test } \\
\text { results }\end{array}$} & \multicolumn{2}{c}{$\begin{array}{c}\text { Laboratory test } \\
\text { results }\end{array}$} \\
\hline ZJ4 & 189.7 & 60.41 & 39.52 & 54.67 & 34.27 \\
ZJ2 & 176.7 & 65.06 & 34.02 & 59.48 & 30.05 \\
ZJ1 & 170.7 & 69.93 & 28.81 & 66.25 & 27.02 \\
\hline
\end{tabular}

The evolution models based on in-situ test results are used as the upper bounds of cohesion and friction angle. The evolution models based on laboratory test results are used as the lower bounds of cohesion and friction angle.

The evolution curves of cohesion and friction angle of the SRM with the test locations elevation are shown in Fig. 16. The evolution models of cohesion and friction angle of the SRM with the elevation are shown in Eqs. (5)-(10). 

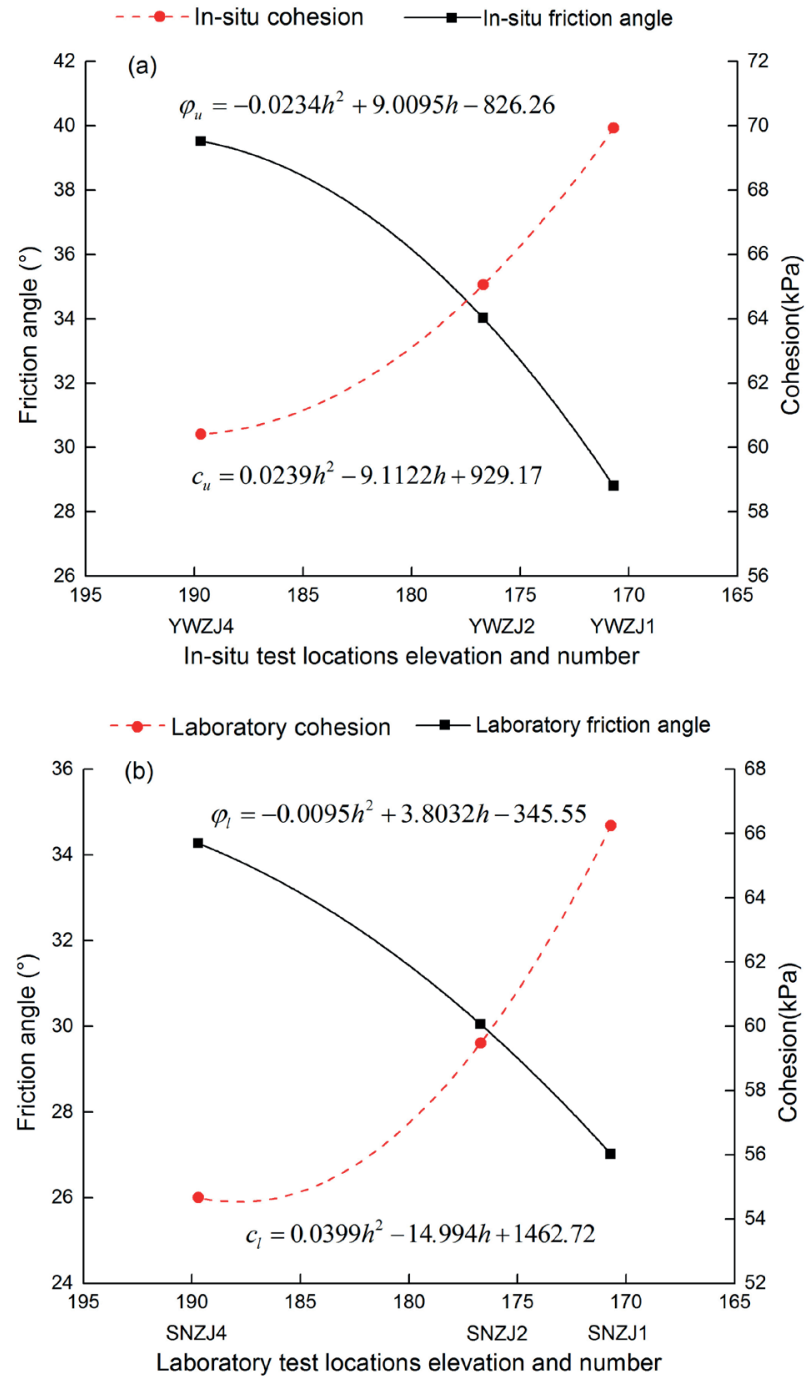

Fig. 16 Evolution curves of shear strength parameters with test location elevation (a) In-situ test results (upper bounds), (b) Laboratory test results (lower bounds)

Evolution model of cohesive of the SRM with elevation (upper bounds):

$c_{u}=0.0239 h^{2}-9.1122 h+929.17$.

Evolution model of cohesive of the SRM with elevation (lower bounds):

$c_{l}=0.0399 h^{2}-14.994 h+1462.72$,

$\left[c_{0}\right] \leq c_{l}<c_{u} \leq[c]$.

Evolution model of friction angle of the SRM with elevation (upper bounds):

$\varphi_{u}=-0.0234 h^{2}+9.0095 h-826.26$.

Evolution model of friction angle of the SRM with elevation (lower bounds): $\varphi_{l}=-0.0095 h^{2}+3.8032 h-345.55$,

$\left[\varphi_{0}\right] \leq \varphi_{l}<\varphi_{u} \leq[\varphi]$.

Where, $c_{u}$ and $c_{l}$ are the lower and upper bounds of the cohesion of SRM at any elevation, $(\mathrm{kPa}) ; h$ is the elevation at any location, $(\mathrm{m}) ;\left[c_{0}\right]$ and $[c]$ are the minimum and maximum values of cohesion of SRM, (kPa); $\varphi_{u}$ and $\varphi_{l}$ are the lower and upper bounds of the friction angle of SRM at any elevation, $\left({ }^{\circ}\right) ;\left[\varphi_{0}\right]$ and $[\varphi]$ are the minimum and maximum values of friction Angle of SRM, $\left(^{\circ}\right)$.

\section{Conclusions}

In order to study the influence of spatial distribution on the shear mechanical properties of the SRM, this paper selects three test locations along the slope and selects two test locations along the transverse slope direction, and carries out in-situ and laboratory large-scale direct shear test, particle sieving analysis, water content test and natural density test. The main conclusions are as follows:

1. The spatial position affects the peak strength of the SRM. Under the same normal stress, the peak strength decreases with the decrease of the elevation, and the decrease rate is similar along the slope direction and the transverse slope direction.

2. The spatial position affects the cohesion and friction angle of the SRM. With the decrease of the elevation of the test location along the slope, the total strengthening degree of cohesion is $0.36 \mathrm{kPa} / \mathrm{m}-0.61 \mathrm{kPa} / \mathrm{m}$, and the total deterioration degree of cohesion is $0.32 \% \mathrm{~m}-0.56 \% \mathrm{~m}$. Although the elevations of the two test locations along the transverse slope have some differences, the changes of cohesion and friction angle are not obvious.

3. The evolution mechanisms of the cohesion and friction angle of the SRM with the spatial position are as follows: First, under the action of gravitational force, the geological materials move from upper elevations to lower elevations, causing the decrease of the rock content; second, the lower the elevation along the slope, the greater the thrust generated by the slope, and the more broken and smaller the size of the rock blocks in the SRM, resulting in the decrease of the rock content; finally, the seepage drag force generated by rainfall in the slope body will bring the fine particles in the SRM from high to low, which is also the cause of the decrease of the rock content along the slope. 
4. According to the data obtained from the in-situ and laboratory direct shear tests of the SRM, the evolution model of the cohesion and friction angle along the slope direction is established, which can provide a reference for the determination of shear strength parameters of the SRM in slope stability calculation.

\section{References}

[1] Xu, W. J., Yue, Z. Q., Hu, R. L. "Study on the mesostructure and mesomechanical characteristics of the soil-rock mixture using digital image processing based finite element method", International Journal of Rock Mechanics and Mining Sciences, 45(5), pp. 749$762,2008$.

https://doi.org/10.1016/j.ijrmms.2007.09.003

[2] Yang, Y. T., Sun, G. H., Zheng, H., Qi, Y. "Investigation of the sequential excavation of a soil-rock-mixture slope using the numerical manifold method", Engineering Geology, 256, pp. 93-109, 2019. https://doi.org/10.1016/j.enggeo.2019.05.005

[3] Kalender, A., Sonmez, H., Medley, E., Tunusluoglu, C., Kasapoglu, K. E. "An approach to predicting the overall strengths of unwelded bimrocks and bimsoils", Engineering Geology, 183, pp. 65-79, 2014.

https://doi.org/10.1016/j.enggeo.2014.10.007

[4] Poggio, L., Gimona, A., Spezia, L., Brewer, M. J. "Bayesian spatial modelling of soil properties and their uncertainty: The example of soil organic matter in Scotland using R-INLA", Geoderma, 277, pp. 69-82, 2016.

https://doi.org/10.1016/j.geoderma.2016.04.026

[5] Zhang, Y. C., Deng, H. F., Wang, W., Duan, L. L., Zhi, Y. Y., Li, J. L. "The Dynamic Response Law of Bank Slope under Water-Rock Interaction", Advances in Civil Engineering, Article ID: 1306575, 2018.

https://doi.org/10.1155/2018/1306575

[6] Li, K. S., Lumb, P. "Probabilistic design of slopes", Canadian Geotechnical Journal, 24(4), pp. 520-535, 1987.

https://doi.org/10.1139/t87-068

[7] Cho, S. E. "Probabilistic Assessment of Slope Stability That Considers the Spatial Variability of Soil Properties", Journal of Geotechnical and Geoenvironmental Engineering, 136(7), pp. 975984, 2010

https://doi.org/10.1061/(ASCE)GT.1943-5606.0000309

[8] Luo, Z. S., Li, J. L., Jiang, Q., Zhang, Y. C., Huang, Y. S., Assefa, E., Deng, H. F. "Effect of the Water-Rock Interaction on the Creep Mechanical Properties of the Sandstone Rock", Periodica Polytechnica Civil Engineering, 62(2), pp. 451-461, 2018. https://doi.org/10.3311/PPci.11788

[9] Griffiths, D. V., Huang, J. S., Fenton, G. A. "Influence of Spatial Variability on Slope Reliability Using 2-D Random Fields", Journal of Geotechnical and Geoenvironmental Engineering, 135(10), pp. 1367-1378, 2009. https://doi.org/10.1061/(ASCE)GT.1943-5606.0000099

[10] Lumb, P. "Safety factors and the probability distribution of soil strength", Canadian Geotechnical Journal, 7(3), pp. 225-242, 1970. https://doi.org/10.1139/t70-032

\section{Acknowledgement}

This research was sponsored by the National Natural Science Funds (no. 51439003), and the Research Fund for Excellent Dissertation of China Three Gorges University (no. 2018BSPY008).

[11] Tang, X. S., Li, D. Q., Wang, X. G., Phoon, K. K. "Statistical characterization of shear strength parameters of rock mass for hydropower projects in China", Engineering Geology, 245, pp. 258-265, 2018. https://doi.org/10.1016/j.enggeo.2018.09.006

[12] Rahardjo, H., Satyanaga, A., Leong, E. C., Ng, Y. S., Pang, H. T. C. "Variability of residual soil properties", Engineering Geology, 141-142, pp. 124-140, 2012. https://doi.org/10.1016/j.enggeo.2012.05.009

[13] Uzielli, M., Vannucchi, G., Phoon, K. K. "Random field characterization of stress-normalized cone penetration testing parameters", Géotechnique, 55(1), pp. 3-20, 2005. https://doi.org/10.1680/geot.55.1.3.58591

[14] Brejda, J. J., Moorman, T. B., Smith, J. L., Karlen, D. L., Allan, D. L., Dao, T. H. "Distribution and Variability of Surface Soil Properties at a Regional Scale", Soil Science Society of America Journal, 64(3), pp. 974-982, 2000. https://doi.org/10.2136/sssaj2000.643974x

[15] Wang, Y. L., Zhao, Y. F., Zhang, H. T., Lin, X. C. "基于二维正态 分布的岩体抗剪强度参数取值范围确定" (2-D normal distribution-based study on parameter selecting range for shear strength of rock mass), Water Resources and Hydropower Engineering, 48, pp. 74-78, 2017. (in Chinese) https://doi.org/10.13928/j.cnki.wrahe.2017.02.013

[16] Cheng, A. P., Xiao, S., Xu, M. G., Wang, P., Liu, Y. Z. "基于广 义Hoek-Brown准则的节理岩体强度及变形参数随机分析" (Stochastic analysis of strength and deformation parameters of jointed rock mass based on generalized Hoek-Brown criterion), Rock and Soil Mechanics, 38, pp. 205-213, 2017. (in Chinese) https://doi.org/10.16285/j.rsm.2017.01.026

[17] Samui, P., Kim, D., Viswanathan, R. "Spatial variability of rock depth using adaptive neuro-fuzzy inference system (ANFIS) and multivariate adaptive regression spline (MARS)", Environmental Earth Sciences, 73(8), pp. 4265-4272, 2015. https://doi.org/10.1007/s12665-014-3711-X

[18] Zhao, Y. X., Liu, Z. X. "Numerical Experiments on Triaxial Compression Strength of Soil-Rock Mixture", Advances in Civil Engineering, 2019, Article ID: 8763569, 2019.

https://doi.org/10.1155/2019/8763569

[19] Yan, Y., Zhao, J. F., Ji, S. Y. "块石含量和空间分布对土石混合 体抗剪强度影响的离散元分析" (Discrete element analysis of the influence of rock content and rock spatial distribution on shear strength of rock-soil mixtures), Engineering Mechanics, 34, pp.146156, 2017. (in Chinese) https://doi.org/10.6052/j.issn.1000-4750.2016.01.0002

[20] Vallejo, L. E., Mawby, R. "Porosity influence on the shear strength of granular material-clay mixtures", Engineering Geology, 58(2), pp. $125-136,2000$. https://doi.org/10.1016/S0013-7952(00)00051-X 
[21] Wei, H. Z., Xu, W. J., Wei, C. F., Meng, Q. S. "Influence of water content and shear rate on the mechanical behavior of soil-rock mixtures", Science China Technological Sciences, 61(8), pp. 11271136, 2018

https://doi.org/10.1007/s11431-017-9277-5

[22] Xu, W. J., Hu, R. L., Tan, R. J. "Some geomechanical properties of soil-rock mixtures in the Hutiao Gorge area, China", Géotechnique, 57, pp. 255-264, 2007.

https://doi.org/10.1680/geot.2007.57.3.255

[23] Zhang, H. Y., Xu, W. J., Yu, Y. Z. "Triaxial tests of soil-rock mixtures with different rock block distributions", Soils and Foundations, 56(1), pp. 44-56, 2016

https://doi.org/10.1016/j.sandf.2016.01.004

[24] Matteo, L. D., Valigi, D., Ricco, R. "Laboratory shear strength parameters of cohesive soils: variability and potential effects on slope stability", Bulletin of Engineering Geology and the Environment, 72(1), pp. 101-106, 2013

https://doi.org/10.1007/s10064-013-0459-6
[25] Xu, W. J., Hu, R. L., Yue, Z. Q., Zhang, R., Wang, G. L. "基于数字 图像分析及大型直剪试验的土石混合体块石含量与抗剪强度关 系研究" (Research on relationship between rock block proportion and shear strength of soil-rock mixtures based on digital image analysis and large direct shear test), Chinese Journal of Rock Mechanics and Engineering, 27(5), pp. 996-1007, 2008. (in Chinese) https://doi.org/10.3321/j.issn:1000-6915.2008.05.016

[26] Sun, S. R., Zhu, F., Wei, J. H., Wang, W. C., Le, H. L. "Experimental Study on Shear Failure Mechanism and the Identification of Strength Characteristics of the Soil-Rock Mixture", Shock and Vibration, Article ID: 7450509, 2019. https://doi.org/10.1155/2019/7450509

[27] Li, W. S., Ding, X. L., Wu, A. Q., Xiong, S. H. "蓄水对三峡库区土 石混合体直剪强度参数的弱化程度研究" (Shear strength degeneration of soil and rock mixture in Three Gorges Reservoir bank slopes under influence of impounding), Rock and Soil Mechanics, 28, pp. 1338-1342, 2007. (in Chinese) https://doi.org/10.16285/j.rsm.2007.07.010 